medRxiv preprint doi: https://doi.org/10.1101/2020.12.18.20248479; this version posted December 22, 2020. The copyright holder for this preprint (which was not certified by peer review) is the author/funder, who has granted medRxiv a license to display the preprint in perpetuity.

It is made available under a CC-BY-NC-ND 4.0 International license .

\title{
Population Changes in Seroprevalence among a Statewide Sample in the United States
}

\section{Author List:}

Kristen Malecki ${ }^{1, *}$, Maria Nikodemova ${ }^{1}$, Amy Schultz $^{1}$, Matt Walsh ${ }^{1}$, Andy Bersch $^{1}$, Ajay Sethi ${ }^{1}$, Paul Peppard ${ }^{1}$, Corinne Engelman ${ }^{1}$, Lisa Cadmus-Bertram² ${ }^{2}$ Nasia Safdar ${ }^{3}$, Allen Batemen ${ }^{4}$, Ryan Westergaard ${ }^{3,4}$

\section{Affiliations:}

1. Department of Population Health Sciences, University of Wisconsin Madison School of Medicine and Public Health, Madison, WI, USA.

2. Department of Kinesiology, University of Wisconsin Madison, Madison, WI, USA.

3. Department of Medicine, University of Wisconsin Madison School of Medicine and Public Health, Madison, WI, USA.

4. Wisconsin State Laboratory of Hygiene, University of Wisconsin Madison School of Medicine and Public Health, Madison, WI, USA.

5. Wisconsin Department of Health Services, Madison, WI, USA

\section{Corresponding Author*: Kristen Malecki, PhD, MPH. Associated Professor, Department of} Population Health Sciences, University of Wisconsin Madison School of Medicine and Public Health, Madison, WI, USA. kmalecki@wisc.edu

\begin{abstract}
Antibody surveillance provides essential information for public health officials to work with communities to discuss the spread and impact of COVID-19 in communities. At the state of the new severe acute respiratory syndrome coronavirus 2 (SARS-CoV-2) pandemic in the diagnostic testing was limited with many asymptomatic cases. Irrespective of symptom severity, antibodies develop within two to three weeks after disease onset and may persist 6 months or more, antibody surveillance is an important tool for tracking trends in past infections across diverse populations. This study includes adults and children recruited from a statewide sample of past 2014-2020 Survey of the Health of Wisconsin (SHOW) participants. SHOW, an ongoing population-based health examination study including a randomly selected sample of households, partnered with the Wisconsin Department of Health Services and the Wisconsin State Laboratory of Hygiene to conduct longitudinal antibody surveillance using the Abbott Architect SARS-CoV-2 IgG antibody test. WAVEs I and II of three planned WAVES were complete in mid-summer to late fall respectively, WAVE III is planned for early 2021. From WAVE I to WAVE II, crude estimates of seroprevalence in the total study population increased four to five-fold from $1.9 \%$ to $7.3 \%$. Within the statewide probability sample, weighted estimates increased from an estimated $1.6 \%$ (95\% Cl:0.6-2.5\%) seropositivity to $6.8 \%$ (95\% Cl:4.3-9.4\%). Seroprevalence varied by health region in both waves, and significant disparities in smaller population groups were identified. Although there was no gender difference observed in WAVE I, seropositivity rates was higher in men $9.4 \%(95 \% \mathrm{Cl}: 4.3,14.3)$ compared to women $4.3 \%$ $(2.7-5.3 \%)$ in WAVE II. This public health and academic partnership provides critical data for public health response to the pandemic and lays the foundation for future research into longerterm immunity, health impacts and population level disparities.
\end{abstract}


Background: In the United States, the COVID-19 pandemic caused by the new severe acute respiratory syndrome coronavirus 2 (SARS-CoV-2) was recognized as a significant public health threat in March of 2020. Scaling up of diagnostic testing was slow at the start, particularly in non-urban settings and non-hospitalized individuals. Community spread is linked to many asymptomatic or mild cases[1]. Consequently, case counts based on antigen testing alone likely underestimate the true number of infections. Antibodies develop within two to three weeks after disease onset [2] for SARS-CoV-2 and may persist 6 months or more in some individuals[3-5] or may decline within 3-5 months after infection[6-10]. By providing an indication of past infection, antibody surveillance therefore provides a means to examine trends in antibody prevalence in the population over time [11].

Methods: This study includes a longitudinal sample of adults recruited from the statewide Survey of the Health of Wisconsin (SHOW) study. Individuals were eligible if they had participated in SHOW health examination protocols between 2014-2016 or were included in the special population oversample conducted in the city of Milwaukee during 2018-2019. This antibody surveillance study was designed in partnership with the Wisconsin Department of Health Services (DHS).

Three waves of repeated blood sample collection among SHOW participants were planned across the entire state. WAVE I collection occurred in early July through August 2020; WAVE II began in late October and continued through early December. WAVE III is planned for early 2021. Twelve sample collection sites were identified across Wisconsin (e.g., health departments, churches, and community-based organizations). Both urban and rural locations were included. Data collection was conducted in English except for one site in Milwaukee that offered Spanish interpreters. Each site was equipped with a small cooler and centrifuge. Participants were screened for fever, COVID-19 symptoms and known past exposures. Those with active COVID-19 infection or COVID-19 exposure within the past 2 weeks were excluded. Blood samples were collected by trained phlebotomists and processed in the field. . The samples were then collected by currier each evening and sent immediately to the Wisconsin State Laboratory of Hygiene, where they were processed using the Abbott Architect SARS-CoV$2 \lg G$ antibody test, with estimated specificity of $99.6 \%[11,12]$. The statewide surveillance was deemed public health exempt, however, additional approval included consent for use of data and additional sample collection for future COVID-19 research was approved by the University of Wisconsin Health Sciences Institutional Review Board (IRB). Further details on study protocols are available from study investigators.

Findings: A total of 1056 individuals were tested in WAVE I and 1070 in WAVE II, corresponding to an average response rate of $39-40 \%$ among all eligible participants. Of these, 996 WAVE I and 994 WAVE II participants were in the original statewide population-based probability sample and were used to estimate weighted statewide estimates reported in Table 1. From WAVE I to WAVE II, crude estimates of seroprevalence in the total study population increased from $1.9 \%$ to $7.3 \%$. Within the statewide probability sample, weighted estimates increased from an estimated $1.6 \%$ (95\% Cl:0.6-2.5\%) seropositivity to $6.8 \%$ (95\% Cl:4.3-9.4\%). Seroprevalence varied by health region in both waves. Although there was no gender difference observed in WAVE I, seropositivity rates was higher in men $9.4 \%$ (95\% Cl:4.3, 14.3) compared to women $4.3 \%(2.7-5.3 \%)$ in WAVE II. Health regions are defined by the Wisconsin Department of Health Services to represent geographic service areas for local and state public health practitioners. In WAVE I, the greatest proportion of positive tests was detected in the Southeastern region of the state, home to Milwaukee, the largest metropolitan area in the state (3.1\% positive; $95 \% \mathrm{Cl}: 1.4-4.9 \%)$; this increased to $9.3 \%(95 \% \mathrm{Cl}: 3.3-15.1 \%)$ in WAVE II. 
The greatest change in antibody-positive results from WAVE I to WAVE II was in the North and Northeast from $1.7 \%(0.0-4.3 \%)$ to $8.7 \%(95 \% \mathrm{Cl}: 5.0-12.4 \%)$. Prevalence also varied by age and race-ethnicity with the highest WAVE II prevalence among 45-64 year-olds at 8.1\% (5.6$10.7 \%$ ) up from $1.9 \%$ positive in WAVE I and compared to $6.1 \%(1.5-10.8 \%)$ among participants younger than 44 and $6.4 \%$ positive (3.3-9.5\%) in those older than 65 . Self-identified Non-whites $(n=133)$ also had a higher prevalence of $8.3(0.3-16.4 \%)$ compared to Non-Hispanic Whites $(n=861)$ with $6.5 \%(3.8-9.2 \%)$. Among the non-white participants, $n=55$ were among a LatinX population oversample recruited from a largely industrial and working-class community on Milwaukee's south side. Of these individuals, over $25 \%$ had positive antibodies measured during WAVE II.

A total of 876 individuals participated in both WAVE I and WAVE II. Of the 18 that tested positive for antibodies in WAVE I and participated in WAVE II, 6 (33\%) had a negative antibody test in WAVE II.

There were 67 participants 18 years of age or younger in WAVE I and 80 in WAVE II. No children were positive in the WAVE I, the prevalence on among child participants in WAVE II was $10 \%$.

Interpretation: Results show an overall four to fivefold increase in the prevalence of antibodies across the state of Wisconsin from the first sample collection in July and August to the second sample collection in later October through early December. Regional variation in trends is consistent with statewide testing results and mirror the overall trends in COVID-19 infections in Wisconsin. The antibody testing suggests that as of early November 2020, just prior to a second statewide spike in COVID-19 infections, over $90 \%$ of the state's population did not have SARSCoV-2 antibodies (whether because of lack of exposure to SARS-CoV-2, or because infection had occurred, but antibodies were no longer detectable). The disparities in seroprevalence among special population samples indicate significantly higher burden in these groups, likely resulting from higher representation of front-line essential workers, health care employees, and households living in more crowded conditions. However, additional research is needed to better understand the significant sources of disparities among these populations. While it is unclear how long individuals will have detectable levels of antibodies after a past infection of COVID-19, results do reflect the increasing trends of COVID-19 infections that occurred between late Spring and Fall across the state of Wisconsin. Further investigation regarding symptom severity, exposure and lingering side effects will provide additional insights into the long term impacts of COVID-19 infection on immunity and health outcomes. The third WAVE of antibody testing in this population is planned for late February and early March 2020.

Funding: The Wisconsin Department of Health Services and The Wisconsin Partnership Program.

Research in context: This is one of a few local and global population-based studies generated from a random statewide sample of adults and children to show that antibody prevalence follows infections in the population. Our observation that one third of participants who tested antibody positive at WAVE I did not retest positive at WAVE II suggests that antibodies are not always long-lasting, and the implications for long-term immunity remain unknown. It is also important to point out that some changes could be due to specificity of the test itself. At $99.6 \%$ specificity, we would expect a portion of the tests in both rounds are due to false positives, but it is hard to ascertain how this is truly impacting study results $[13,14]$. Nonetheless, these data provide essential information for public health officials to work with communities to discuss the spread 
medRxiv preprint doi: https://doi.org/10.1101/2020.12.18.20248479; this version posted December 22, 2020. The copyright holder for this preprint (which was not certified by peer review) is the author/funder, who has granted medRxiv a license to display the preprint in perpetuity.

It is made available under a CC-BY-NC-ND 4.0 International license.

and impact of COVID-19 in the community. Moving forward, the long-term implications of these past infections on health and well-being can be monitored as part of the ongoing Survey of the Health of Wisconsin research program.

Acknowledgements: We would like to acknowledge all past SHOW participants willing to take place in this surveillance effort. Additional acknowledgements to SHOW Program Manager Jen Tratnyek and her team for supporting logistics, the SHOW phlebotomy coordinator Jonathan Cabezas-Olcoz, and field coordinator Doug Esselman, and lead administrative support from Ben Young for study organization, recruitment and coordination, Allison Rodriguez for Spanish translation and Jacqueline Cronin for data dissemination and outreach efforts. Further thanks to the various sample collection site partners across the state of Wisconsin who opened their doors for this work. The Wisconsin State Laboratory of Hygiene staff also played a key role in supporting these efforts in coordination with the SHOW program and were responsible for coordination of testing and reporting of results to the SHOW program for further dissemination of results to participants. 
Table 1 - Past Antibody COVID-19 Community Survey Seroprevalence Results, WAVE I and WAVE II

\begin{tabular}{|c|c|c|c|c|c|c|c|c|}
\hline \multirow[b]{2}{*}{ Select Factors } & \multirow[b]{2}{*}{$\mathrm{N}$} & \multicolumn{3}{|c|}{ WAVE I July -Early August, 2020} & \multicolumn{4}{|c|}{ WAVE II Late October- Early December, 2020} \\
\hline & & $\begin{array}{l}\text { Crude } \\
\text { Percentage }\end{array}$ & $\begin{array}{l}\text { Weighted } \\
\text { Percentage }\end{array}$ & $\begin{array}{l}\text { Weighted 95\% } \\
\mathrm{Cl}^{*}\end{array}$ & $\mathrm{~N}$ & $\begin{array}{l}\text { Crude } \\
\text { Percentage }\end{array}$ & $\begin{array}{l}\text { Weighted } \\
\text { Percentage } \\
*\end{array}$ & $\begin{array}{l}\text { Weighted } \\
95 \% \mathrm{Cl}^{*}\end{array}$ \\
\hline TOTAL & 996 & 1.4 & 1.6 & $(0.6,2.5)$ & 994 & 6.5 & 6.8 & $(4.3,9.4)$ \\
\hline \multicolumn{9}{|l|}{ Age (on June 21, 2020) } \\
\hline 12 to 44 & & 1.3 & 1.4 & $(0.0,2.9)$ & 297 & 5.7 & 6.1 & $(1.5,10.8)$ \\
\hline 45 to 64 & & 2.0 & 1.9 & $(0.2,3.6)$ & 318 & 8.2 & 8.1 & $(5.6,10.7)$ \\
\hline 65 or older & & 1.1 & 1.5 & $(0.1,3.0)$ & 379 & 5.8 & 6.4 & $(3.3,9.5)$ \\
\hline \multicolumn{9}{|l|}{ Gender } \\
\hline Male & & 1.2 & 1.6 & $(0.8,3.2)$ & 405 & 8.2 & 9.4 & $(4.3,14.5)$ \\
\hline Female & & 1.7 & 1.6 & $(0.8,3.2)$ & 589 & 5.4 & 4.3 & $(2.7,5.8)$ \\
\hline \multicolumn{9}{|l|}{ Race / Ethnicity } \\
\hline Non-Hispanic white & & 1.2 & 1.3 & $(0.1,2.4)$ & 861 & 6.3 & 6.5 & $(3.8,9.2)$ \\
\hline \multirow[t]{2}{*}{ Hispanic or non-white } & & 4.0 & 5.6 & $(0.0,14.5)$ & 133 & 8.3 & 8.3 & $(0.3,16.4)$ \\
\hline & & 5.0 & 2.3 & $(0.0,7.0)$ & & & & \\
\hline \multicolumn{9}{|c|}{ Poverty (at previous survey 2014-2019) } \\
\hline$\geq 200 \% \mathrm{FPL}$ & & 1.8 & 1.0 & $(0.0,3.1)$ & & 6.8 & 7.5 & $(4.2,10.7)$ \\
\hline$<200 \% \mathrm{FPL}$ & & 1.0 & 1.1 & $(0.1,2.0)$ & & 5.8 & 5.2 & $(1.1,9.4)$ \\
\hline Health Region & & 2.8 & 2.7 & $(0.3,5.1)$ & & & & \\
\hline SE & & & & & 346 & 7.8 & 9.2 & $(3.3,15.1)$ \\
\hline$S$ & & 2.6 & 3.1 & $(1.3,4.9)$ & 98 & 4.1 & 2.4 & $(0.6,4.3)$ \\
\hline $\mathrm{W}$ & & NA & NA & NA & 276 & 4.0 & 3.9 & $(2.9,4.9)$ \\
\hline$N \& N E$ & & 0.3 & 0.3 & $(0.0,0.7)$ & 274 & 8.4 & 8.7 & $(5.0,12.4)$ \\
\hline
\end{tabular}


Table 2. Surveillance Recruitment and Response Rates for COVID-19 Antibody Testing*

\begin{tabular}{|c|c|c|c|c|c|}
\hline Sample WAVE I & Eligible & Participate & $\begin{array}{l}\text { Response } \\
\text { Rate (\%) }\end{array}$ & $\begin{array}{l}\text { Positive } \\
\text { Tests }\end{array}$ & \% Positive \\
\hline 2014-2016 & 2228 & 952 & 42.7 & 13 & 1.4 \\
\hline 2018-2019 (probability) & 273 & 47 & 17.2 & 1 & 2.1 \\
\hline 2018-2019 (convenience) & 169 & 33 & 19.5 & 2 & 6.1 \\
\hline Latinx pilot & 104 & 24 & 23.1 & 4 & 16.7 \\
\hline Sample WAVE II & Eligible & Participate & $\begin{array}{l}\text { Response } \\
\text { Rate }\end{array}$ & $\begin{array}{l}\text { Positive } \\
\text { Tests }\end{array}$ & $\%$ Positive \\
\hline 2014-2016 & 2228 & 930 & 41.7 & 61 & 6.6 \\
\hline 2018-2019 (probability) & 273 & 64 & 23.4 & 4 & 6.3 \\
\hline 2018-2019 (convenience) & 169 & 38 & 22.5 & 3 & 7.9 \\
\hline Latinx pilot & 104 & 38 & 36.5 & 10 & 26.3 \\
\hline
\end{tabular}

*NOTE: Study sample individuals were asked to refrain from participation if they had an active COVID-19 infection or known COVID-19 exposure in the last two weeks. 
medRxiv preprint doi: https://doi.org/10.1101/2020.12.18.20248479; this version posted December 22, 2020. The copyright holder for this preprint (which was not certified by peer review) is the author/funder, who has granted medRxiv a license to display the preprint in perpetuity.

It is made available under a CC-BY-NC-ND 4.0 International license .

\section{REFERENCES}

1. Long, Q.-X., et al., Clinical and immunological assessment of asymptomatic SARS-CoV2 infections. Nature Medicine, 2020. 26(8): p. 1200-1204.

2. Wu, J., et al., SARS-CoV-2 infection induces sustained humoral immune responses in convalescent patients following symptomatic COVID-19. medRxiv, 2020: $p$. 2020.07.21.20159178.

3. Dan, J.M., et al., Immunological memory to SARS-CoV-2 assessed for up to eight months after infection. bioRxiv, 2020: p. 2020.11.15.383323.

4. Pradenas, E., et al., Stable neutralizing antibody levels six months after mild and severe COVID-19 episode. bioRxiv, 2020: p. 2020.11.22.389056.

5. Wajnberg, A., et al., Robust neutralizing antibodies to SARS-CoV-2 infection persist for months. Science, 2020. 370(6521): p. 1227-1230.

6. Ibarrondo, F.J., et al., Rapid Decay of Anti-SARS-CoV-2 Antibodies in Persons with Mild Covid-19. New England Journal of Medicine, 2020. 383(11): p. 1085-1087.

7. Korte, W., et al., SARS-CoV-2 IgG and IgA antibody response is gender dependent; and IgG antibodies rapidly decline early on. The Journal of infection, 2020: p. S01634453(20)30567-3.

8. Röltgen, K., et al., SARS-CoV-2 Antibody Responses Correlate with Resolution of RNAemia But Are Short-Lived in Patients with Mild Illness. medRxiv, 2020: p. 2020.08.15.20175794.

9. Seow, J., et al., Longitudinal evaluation and decline of antibody responses in SARSCoV-2 infection. medRxiv, 2020: p. 2020.07.09.20148429.

10. Yin, S., et al., Longitudinal anti-SARS-CoV-2 antibody profile and neutralization activity of a COVID-19 patient. The Journal of infection, 2020. 81(3): p. e31-e32.

11. Ainsworth, M., et al., Performance characteristics of five immunoassays for SARS-CoV2: a head-to-head benchmark comparison. The Lancet Infectious Diseases, 2020. 20(12): p. 1390-1400.

12. Bryan, A., et al., Performance Characteristics of the Abbott Architect SARS-CoV-2 IgG Assay and Seroprevalence in Boise, Idaho. Journal of Clinical Microbiology, 2020. 58(8): p. e00941-20.

13. Luchsinger, L.L., et al., Serological Assays Estimate Highly Variable SARS-CoV-2 Neutralizing Antibody Activity in Recovered COVID-19 Patients. Journal of Clinical Microbiology, 2020. 58(12): p. e02005-20.

14. McAdam, A., et al. SARS-CoV-2 Testing: Sensitivity Is not the Whole Story. 2020. 2020. 